\title{
Phytochemical composition of Helichrysum arenarium (L.) Moench essential oil (aerial parts) from Turkey
}

\author{
Stanko Stankov ${ }^{1}$, Hafize Fidan ${ }^{1}$, Nadezhda Petkova ${ }^{1}$, \\ Albena Stoyanova ${ }^{1}$, Ivaila Dincheva ${ }^{2}$, Hulya Dogan ${ }^{3}$, Belgin Cosge \\ Senkal ${ }^{3}$, Tansu Uskutoglu ${ }^{3}$, Hatice Bas $^{3}$, Gungor Yilmaz ${ }^{3}$
}

\author{
1 - University of Food Technologies, Plovdiv, Bulgaria \\ 2 - AgroBioInstitute, Sofia, Bulgaria \\ 3 - Yozgat Bozok University, Yozgat, Turkey
}

\section{Keywords:}

\section{Helichrysum arenarium $\mathrm{L}$. Oil \\ Essential \\ Phenolic \\ Antioxidant}

\section{Article history:}

\section{Received}

29.03.2020

Received in revised form

03.09.2020

Accepted

30.09 .2020

\section{Corresponding} author:

\section{Hafize Fidan}

E-mail:

hfidan@ abv.bg

DOI:

10.24263/2304974X-2020-9-3-3

\section{Abstract}

Introduction. The aim of the present study was to determine the phytochemical composition of Helichrysum arenarium (L.) Moench (aerial parts) essential oil and extracts obtained from Turkey as a source of bioactive components for the food, cosmetics and pharmaceutical industry.

Materials and methods. The flower essential oil was obtained by hydrodistillation for $2 \mathrm{~h}$ and its composition was analyzed using gas chromatographic analysis (GC/MS). Extracts were obtained from the airdried flowers by treatment with 70 and $90 \%$ ethanol $(1: 5 \mathrm{v} / \mathrm{w})$ in an ultrasonic bath. In the extracts, the total phenolic content was obtained by Folin-Cicalteu method. The total flavonoid content was determined by $\mathrm{Al}\left(\mathrm{NO}_{3}\right)_{3}$ reagents, measured at wavelength $415 \mathrm{~nm}$ against a blank. Antioxidant activity of the extracts was determined using DPPH, ABTS, FRAP, and CUPRAC assay.

Results and discussion. The amount of extracted essential oil was $0.07 \%$ with the main constituents oleic acid (30.28\%), ethyl hexadecanoate (20.19\%), linoleic acid (18.89\%), and sclareol (4.22\%). The composition of the oil predominated by oxygenated hydrocarbons (76.90\%), followed by diterpenes (11.50\%), hydrocarbons $(3.53 \%)$ ), oxygenated sesquiterpenes (3.30\%), phenyl propanoids $(2.93 \%)$, sesquiterpene hydrocarbons $(1.43 \%)$, monoterpene hydrocarbons $(0.34 \%)$, and oxygenated monoterpenes $(0.07 \%)$. The content of the total polyphenols in the $95 \%$ ethanol extracts was $7.56 \mathrm{mg}$ GAE/g dw and the total flavonoids was $3.13 \mathrm{mg} \mathrm{GAE} / \mathrm{g} \mathrm{dw}$, whereas their content in the $70 \%$ ethanol extract were $6.62 \mathrm{mg} \mathrm{GAE} / \mathrm{g} \mathrm{dw}$ and $3.34 \mathrm{mg} \mathrm{GAE} / \mathrm{g} \mathrm{dw}$, respectively. Among the plant samples, $70 \%$ ethanol extract exhibited higher CUPRAC ( $159.46 \mathrm{mM}$ TE/g dw) followed by ABTS radical action decolourization ( $47.53 \mathrm{mM} \mathrm{TE} / \mathrm{g} \mathrm{dw}$ ). The results for ethanol extracts and their antioxidant activity were in accordance with the total phenolic content and the concentration of flavonoids. The flowers of $H$. arenarium were dominated by total carotenoid $(10.68 \mu \mathrm{g} / \mathrm{g} \mathrm{dw})$, followed by total chlorophyll $(51.24 \mu \mathrm{g} / \mathrm{g} \mathrm{dw})$. The content of chlorophyll a $(32.67 \mu \mathrm{g} / \mathrm{g}$ $\mathrm{dw})$ was higher than that of chlorophyll b $(18.57 \mu \mathrm{g} / \mathrm{g} \mathrm{dw})$.

Conclusions. The main compounds of the $H$. arenarium essential oil were oleic acid, ethyl hexadecanoate, linoleic acid, and sclareol. The extracts showed a high level of total phenolic content and antioxidant potential, which make the studied plant species as a potential source of alternative natural antioxidant or a source of biologically active components. 


\section{Introduction}

Helichrysum arenarium L., commonly known as immortelle or everlasting among the population, is a plant with a pronounced potential for use and application in various spheres of life. The immortelle belongs to the genus Helichrysum (Asteraceae family) and includes over 600 species in the world. The genus is represented also in Turkish flora by 27 taxa (21 species and 6 subspecies), and 15 of them are endemic [1].

Due to the wide range of application of the plant, in some regions of the Turkey the plant was cultivated for the purpose of industrial production of essential oil, for use in cosmetics and food industry.

The species is widely used for essential oil isolation, because the oil have economic and pharmaceutical importance as they are used as a plant preservative [2]. The majority of authors confirm that the therapeutical effect of plants is attributed mainly to the presence of flavonoids and polyphenols [3].

In Turkey, the plant has been used only in folk medicine [1], which is a prerequisite for its cultivation for use in other sectors such as food, pharmacy and cosmetics industry.

The literature contains data on the chemical composition of the essential oil obtained from plants growing in different countries of Europe and Asia.

Radusiene and Judzentiene [4] isolated the essential oil from the differently colored (citric-yellow, citric, yellow, orange, yellow-brown and brown) inflorescences of $H$. arenarium growing in Lithuania. Trans-caryophyllene $(8.8 \%), \delta$-cadinene $(8.2 \%)$, and 1,8 cineole $(7.0 \%)$ were the major constituents in essential oils from citric inflorescences. The oil from brown inflorescences contained trans-caryophyllene $(7.8 \%)$, whereas tetradecanoic acid $(7.0 \%)$ was the major constituents of oils from yellow and yellow-brown inflorescences. The main constituents of $H$. arenarium essential oil from China were sesquiterpenes $\beta$ spatulenol (19.9-24.03\%), ledol (6.22-10.02\%), bicyclogermacrene (5.68\%), aromadendrene (5.15\%), and $\alpha$-eudesmol (4.29-4.37\%) [5]. The chemical composition of $H$. arenarium essential oil from Hungary was represented by linalool $(1.7 \%)$, anethole $(3.2 \%)$, carvacrol (3.6\%), and $\alpha$-muurolene (1.3\%) [6].

The analysis of the data showed that the chemical composition of the essential oil was different, which depends on both the method of its obtaining and the soil and climatic conditions of growing the plant.

The $H$. arenarium essential oil demonstrated antimicrobial activity $[7,8]$ against various microorganisms, including pathogenic strains. Other authors, such as Tepe et al. [9] reported the antioxidant activity of the methanol extracts of four Turkish Helichrysum species.

Although the immprtelle plant was extensively investigated in different parts of the world, there were no data in the literature for the determination of secondary metabolites (pigments chlorophyll and carotenoids, essential oil, phenolic compounds and flavonoids) in the flowers of $H$. arenarium growing in Turkey, as well as for the antioxidant activity of its ethanolic extracts.

Therefore, the aim of this study was to determine the phytochemical composition of Helichrysum arenarium (L.) Moench (aerial parts) essential oil and extracts obtained from Turkey as a source of bioactive components for the food, cosmetics and pharmaceutical industry. 


\section{Food Technology}

\section{Materials and methods}

\section{Plant material}

The aerial parts of $H$. arenarium were collected in full flowering stage on 31 July 2018 from Yozgat Akdagmadeni district (39 34.647' N 35 $48.568^{\prime} \mathrm{E}$, altitude $\left.1760 \mathrm{~m}\right)$. Then dried at room temperature $\left(18 \pm 2{ }^{\circ} \mathrm{C}\right)$ and relative humidity of $65 \%$ for 14 days. The samples were packed in plastic bags and stored at $23 \pm 2{ }^{\circ} \mathrm{C}$ until being abalyzed.

\section{Isolation of essential oil}

The moisture of the flowers $(9.91 \% \pm 0.09)$ was determined by drying up to constant weight at $105^{\circ} \mathrm{C}[10]$.

The air-dried flowers were cut to a size of $0.5 \mathrm{~mm}$. The essential oil was isolated by hydrodistillation for $2 \mathrm{~h}$ in a laboratory glass apparatus of the British Pharmacopoeia [11]. The oil obtained was dried over anhydrous sodium sulfate and stored in tightly closed dark vials at $4{ }^{\circ} \mathrm{C}$ until analysis.

\section{Chemical composition of essential oil}

The GC analysis was performed using a GC Agilent 7890A, an HP-5 ms column (30 m x $250 \mu \mathrm{m} \times 0.25 \mu \mathrm{m}$ ), temperature: $35^{\circ} \mathrm{C} / 3 \mathrm{~min}, 5^{\circ} \mathrm{C} / \mathrm{min}$ to $250{ }^{\circ} \mathrm{C}$ for $3 \mathrm{~min}$, total: $49 \mathrm{~min}$; helium as a carrier gas at $1 \mathrm{~mL} / \mathrm{min}$ constant speed, and 30:1 split ratio.

The GC/MS analysis was carried out on an Agilent 5975C mass spectrometer, using helium as a carrier gas, and the same column and temperature as in the GC analysis.

The identification of chemical compounds was done by comparison to their relative retention time and library data. The identified constituents were arranged in order of retention time and quantity in percentage.

\section{Ultrasound-assisted extraction}

The ultrasound-assisted extraction of biologically active substances from air-dried flowers was performed in an ultrasonic bath SIEL UST 5.7-150, Gabrovo, Bulgaria, with frequency $35 \mathrm{kHz}$ and $300 \mathrm{~W}$. The extraction procedure was performed with two solvents with different polarity $95 \%$ and $70 \%$ ethanol in the ratio $(1: 5 \mathrm{v} / \mathrm{w})$. The dried plant materials were weighed in a $50 \mathrm{~mL}$ centrifuge tube with a screw cap and then $20 \mathrm{~mL}$ solvent was added to the sample. The tubes were placed in the ultrasonic bath at $55{ }^{\circ} \mathrm{C}$ for $20 \mathrm{~min}$. The ultrasound-assisted extraction was performed in triplicate. Each extract was filtered and the combined extracts were used for further analysis.

\section{Total phenolic content}

The total phenolic content (TPC) was determined using the Folin-Ciocalteu reagent [12], as the extract $(0.2 \mathrm{~mL})$ was mixed with $1 \mathrm{~mL}$ Folin-Ciocalteu reagent diluted (1:5) and 0.8 $\mathrm{mL} 7.5 \%$ sodium carbonate. After $20 \mathrm{~min}$ at room temperature $\left(25{ }^{\circ} \mathrm{C}\right)$ in darkness, the absorption was measured at wavelength $765 \mathrm{~nm}$ against a blank sample. [13]. 


\section{Food Technology}

\section{Total flavonoids content}

The total flavonoids content was analyzed by $\mathrm{Al}\left(\mathrm{NO}_{3}\right)_{3}$ reagents and measured at wavelength $415 \mathrm{~nm}$ against a blank [14]. The results were presented as mg quercetin equivalents $(\mathrm{QE})$ per $\mathrm{g} \mathrm{dw}$.

\section{Antioxidant activity}

The DPPH radical scavenging activities of flowers were evaluated [15], and the absorbance was measured at wavelength $517 \mathrm{~nm}$. Radical scavenging activity of samples was expressed as $\mathrm{mM}$ Trolox ${ }^{\circledR}$ equivalent (TE) per $\mathrm{g} \mathrm{dw}$.

\section{ABTS radical action decolourization assay}

ABTS radical was generated as an aliquot part of $7.0 \mathrm{mM} 2$,2 azinobis (3)ethylbenzthiazoline--sulfonic acid (ABTS, Sigma) in distilled water was mixed with 2.45 $\mathrm{mM}$ potassium persulfate in distilled water. The reaction was performed for $16 \mathrm{~h}$ at ambient temperature $\left(25^{\circ} \mathrm{C}\right)$ in darkness. Before analyses, $2.0 \mathrm{~mL}$ of generated ABTS.+ solution was diluted with methanol at proportions 1:30 (v/v), to the final absorbance of the working solution about $1.0 \div 1.1$ at wavelength $734 \mathrm{~nm}$. ABTS $^{++}$solution $(2.85 \mathrm{~mL})$ was added to 0.15 $\mathrm{mL}$ extracts. After $15 \mathrm{~min}$ at $37{ }^{\circ} \mathrm{C}$ in darkness, the absorbance was measured at wavelength $734 \mathrm{~nm}$ against methanol. The antioxidant activity was expressed as $\mathrm{mM}$ TE/g dw [13].

\section{Ferric reducing antioxidant power assay (FRAP)}

The FRAP method was performed as previously described [16] and the absorbance was recorded at wavelength $593 \mathrm{~nm}$. The results were expressed as $\mathrm{mM}$ Trolox ${ }^{\circledR}$ equivalent per $\mathrm{g} \mathrm{dw}$.

\section{Cupric reducing antioxidant capacity (CUPRAC) assay}

One $\mathrm{mL} \mathrm{CuCl} \mathrm{Cu}_{2} \times 2 \mathrm{H}_{2} \mathrm{O}, 1 \mathrm{~mL}$ Neocuproine $(7.5 \mathrm{~mL}$ in methanol), $0.1 \mathrm{M}$ ammonium acetate buffer $(1 \mathrm{~mL}), 0.1 \mathrm{~mL}$ extracts and $1 \mathrm{~mL}$ distilled water was mixed. The reaction was performed for $20 \mathrm{~min}$ at $50{ }^{\circ} \mathrm{C}$ in darkness. After cooling the absorbance was measured at wavelength $450 \mathrm{~nm}$. The antioxidant activity was expressed as $\mathrm{mM} \mathrm{TE} / \mathrm{g}$ dw [13].

\section{Total Chlorophylls and Carotenoid content}

For determination of chlorophyll a, chlorophyll b, total chlorophylls and the total carotenoids, the absorbance of $95 \%$ ethanol extracts was measured at three wavelengths 664 $\mathrm{nm}, 648 \mathrm{~nm}$, and $470 \mathrm{~nm}$. The amount of these pigments was calculated according to the formulas $(-4),[17]$.

$$
\begin{gathered}
\text { Chlorophyll a }(\mathrm{Ca})=13.36 \mathrm{~A}_{664 \cdot 2}-5.19 \mathrm{~A}_{648.6} \\
\text { Chlorophyll } \mathrm{b}(\mathrm{Cb})=27.43 \mathrm{~A}_{648 \cdot 6}-8.12 \mathrm{~A}_{664.2} \\
\text { Total Chlorophyll }(\mathrm{a}+\mathrm{b})=5.24 \mathrm{~A}_{664 \cdot 2}+22.24 \mathrm{~A}_{648.6} \\
\text { Total carotenoids }=\left[1000 \mathrm{~A}_{470}-2.13 \mathrm{C}_{\mathrm{a}}-97.64 \mathrm{C}_{\mathrm{b}}\right] / 209
\end{gathered}
$$




\section{Results and discussion}

\section{Chemical composition of essential oil}

In our study, the essential oil content (yield) was $0.07 \% \pm 0.00$ in the plants. The chemical composition of $H$. arenarium essential oil was presented in Table 1.

In the essential oil, 42 constituents representing $97.89 \%$ of the total content were identified. Ten of them were in concentrations over $1 \%$ and the rest 32 constituents were in concentrations under $1 \%$. The main constituents in the plant essential oil (above 3\%) were: oleic acid $(30.28 \%)$, ethyl hexadecanoate $(20.19 \%)$, linoleic acid $(18.89 \%)$, and sclareol $(4.22 \%)$.

The main components' groups were found to be oxygenated hydrocarbons (oleic acid, ethyl hexadecanoate, and linoleic acid), followed by diterpenes (scraleol), hydrocarbons (ntetracosane), oxygenated sesquiterpenes (cedrol), phenylpropanoids (carvacrol), sesquiterpene hydrocarbons, monoterpene hydrocarbons, and oxygenated monoterpenes.

The chemical composition of $H$. arenarium essential oil was previously studied by several researchers [18, 19, 20]. In their paper, Leonardi et al. [18] analyzed essential oils obtained from six species of $H$. arenarium growing in Italy. One hundred seventeen components were identified representing $90.1-98.5 \%$ of the total chemical composition, mainly characterized by sesquiterpenes and monoterpene compounds. Judzentiene and Butkiene [19] studied the essential oil composition of $H$. arenarium of leaves and inflorescences of different colors from natural populations from eastern Lithuania. It was found that the principal constituents were $\beta$-caryophyllene (in three inflorescences and one leaf oil), $\delta$-cadinene (in two leaf samples), octadecane (in one leaf sample) and heneicosane (in one inflorescence sample). Later, in 2019, Judzentiene et al. [20] investigated the chemical composition of the 16 essential oils obtained by hydrodistillation from inflorescences and leaves of $H$. arenarium plants growing in Lithuanian forests. Similarly to the data reported by Leonardi et al. [18], they determined that the main fractions were found to be sesquiterpenes $(29.0-70.1 \%)$ and aliphatics hydrocarbons $(7.7-45.5 \%)$. It is also reported that $\beta$-caryophyllene, $\delta$-cadinene, and octadecane, were among the main constituent of $H$. arenarium essential oil collected in Lithuania. Different species of Helichrysum showed significant differences in chromatographic profiles. The results reported by Juliano et al. [21] showed that the chemical composition of H. microphyllum subsp. tyrrhenicum essential oil s collected in four different regions in South-Western Sardinia, was represented by a significant amount of neryl acetate, $\gamma$-curcumene, and linalool. Kurkcuoglu et al. [22] reported a study for the chemical composition, simultaneously analyzed by GC/FID and GC/MS obtained by the aerial parts of $H$. noeanum Boiss. and $H$. chionophilum Boiss. et Balansa. They reported that the main constituents were identified as hexadecanoic acid, dodecanoic acid, tetradecanoic acid, and decanoic acid. Besides the specificity of studied species the differences between the essential oil composition in this study and that from other studies, reported in the literature, are probably due to the climatic conditions in the respective location where the plants were grown, and also to the plant parts processed and obtained. 
Table 1

Chemical composition of the $H$. arenarium essential oil

\begin{tabular}{|c|c|c|c|}
\hline № & Name & RI & Content, \% \\
\hline 1. & $\alpha$-Pinene & 932 & $0.10 \pm 0.0$ \\
\hline 2. & $p$-Cymene & 1019 & $0.08 \pm 0.0$ \\
\hline 3. & $y$-Terpinene & 1054 & $0.07 \pm 0.0$ \\
\hline 4. & $\beta$-Linalool & 1095 & $0.07 \pm 0.0$ \\
\hline 5. & Borneol & 1165 & $0.10 \pm 0.0$ \\
\hline 6. & n-Dodecane & 1200 & $0.06 \pm 0.0$ \\
\hline 7. & Thymol & 1289 & $0.11 \pm 0.0$ \\
\hline 8. & Carvacrol & 1297 & $2.68 \pm 0.02$ \\
\hline 9. & $\beta$-Caryophyllene & 1417 & $0.56 \pm 0.0$ \\
\hline 10. & Aromadendrene & 1439 & $0.17 \pm 0.0$ \\
\hline 11. & $\alpha$-Caryophyllene & 1453 & $0.13 \pm 0.0$ \\
\hline 12. & Germacrene D & 1484 & $0.11 \pm 0.0$ \\
\hline 13. & $\gamma$-Cadinene & 1513 & $0.23 \pm 0.0$ \\
\hline 14. & $\delta$-Cadinene & 1522 & $0.20 \pm 0.0$ \\
\hline 15. & (2E)-Tridecenol & 1568 & $0.10 \pm 0.0$ \\
\hline 16. & Spathulenol & 1576 & $0.15 \pm 0.0$ \\
\hline 17. & Caryophyllene oxide & 1582 & $0.13 \pm 0.0$ \\
\hline 18. & Viridiflorol & 1591 & $0.21 \pm 0.0$ \\
\hline 19. & Cedrol & 1600 & $0.67 \pm 0.0$ \\
\hline 20. & $\beta$-Cedren-9-one & 1632 & $0.08 \pm 0.0$ \\
\hline 21. & epi- $\alpha$-Cadinol & 1640 & $0.48 \pm 0.0$ \\
\hline 22. & $\alpha$-Cadinol & 1653 & $0.20 \pm 0.0$ \\
\hline 23. & 7-epi- $\alpha$-Eudesmol & 1662 & $0.32 \pm 0.0$ \\
\hline 24. & $\alpha$-Bisabolol & 1685 & $0.10 \pm 0.0$ \\
\hline 25. & Cedroxyde & 1713 & $0.14 \pm 0.0$ \\
\hline 26. & Methyl tetradecanoate & 1722 & $2.79 \pm 0.02$ \\
\hline 27. & (2E,6E)-Farnesyl acetate & 1844 & $0.31 \pm 0.0$ \\
\hline 28. & n-Nonadecane & 1900 & $0.26 \pm 0.0$ \\
\hline 29. & Methyl hexadecanoate & 1922 & $2.54 \pm 0.02$ \\
\hline 30. & Phytol & 1943 & $0.20 \pm 0.0$ \\
\hline 31. & Sclarene & 1974 & $0.30 \pm 0.0$ \\
\hline 32. & Ethyl hexadecanoate & 1997 & $20.19 \pm 0.19$ \\
\hline 33. & n-Eicosane & 2000 & $0.16 \pm 0.0$ \\
\hline 34. & n-Heneicosane & 2100 & $0.18 \pm 0.0$ \\
\hline 35. & Methyl octadecanoate & 2124 & $0.48 \pm 0.0$ \\
\hline 36. & Linoleic acid & 2132 & $18.89 \pm 0.17$ \\
\hline 37. & Oleic acid & 2141 & $30.28 \pm 0.29$ \\
\hline 38. & Sclareol & 2222 & $4.22 \pm 0.04$ \\
\hline 39. & 3a-hydroxy-Manool & 2301 & $0.67 \pm 0.0$ \\
\hline 40. & $3 \alpha$-14,15-dihydro-Manool oxide & 2337 & $2.89 \pm 0.02$ \\
\hline 41. & $3 \alpha$-acetoxy-Manool & 2362 & $2.98 \pm 0.02$ \\
\hline 42. & n-Tetracosane & 2400 & $2.86 \pm 0.02$ \\
\hline \multicolumn{3}{|c|}{ Hydrocarbons, $\%$} & 3.53 \\
\hline \multicolumn{3}{|c|}{ Oxygenated hydrocarbons, $\%$} & 76.90 \\
\hline \multicolumn{3}{|c|}{ Monoterpene hydrocarbons, $\%$} & 0.34 \\
\hline \multicolumn{3}{|c|}{ Oxygenated monoterpenes, $\%$} & 0.07 \\
\hline \multicolumn{3}{|c|}{ Sesquiterpene hydrocarbons, $\%$} & 1.43 \\
\hline \multicolumn{3}{|c|}{ Oxygenated sesquiterpenes, \% } & 3.30 \\
\hline \multicolumn{3}{|c|}{ Phenyl propanoids, \% } & 2.93 \\
\hline \multicolumn{3}{|c|}{ Diterpenes, $\%$} & 11.50 \\
\hline
\end{tabular}




\section{Total phenolic and flavonoid content}

The results for total phenolic and flavonoids content of $H$. arenarium extracts are shown in Figure 1. The total phenolic content of the $95 \%$ ethanol extracts was higher $(7.56 \pm 0.08$ $\mathrm{mg} \mathrm{GAE} / \mathrm{g} \mathrm{dw}$ ) than the other sample. On the other hand, the amount of flavonoids for $70 \%$ ethanol was greater $(3.34 \pm 0.15 \mathrm{QE} / \mathrm{g} \mathrm{dw})$ than that of $95 \%$ ethanol extract. Our results for $70 \%$ ethanol extracts were lower than the results obtained by Babota et al. [23] for the phenolic content (25.17 mg GAE/g dw) and total flavonoid content (27.17 QE/g dw). In a study performed by Albayrak et al. [24] the TPC value ranged from 71.81 to $125.57 \mathrm{mg}$ GAE/g of methanolic extracts of two subspecies of $H$. arenarium from Turkey.

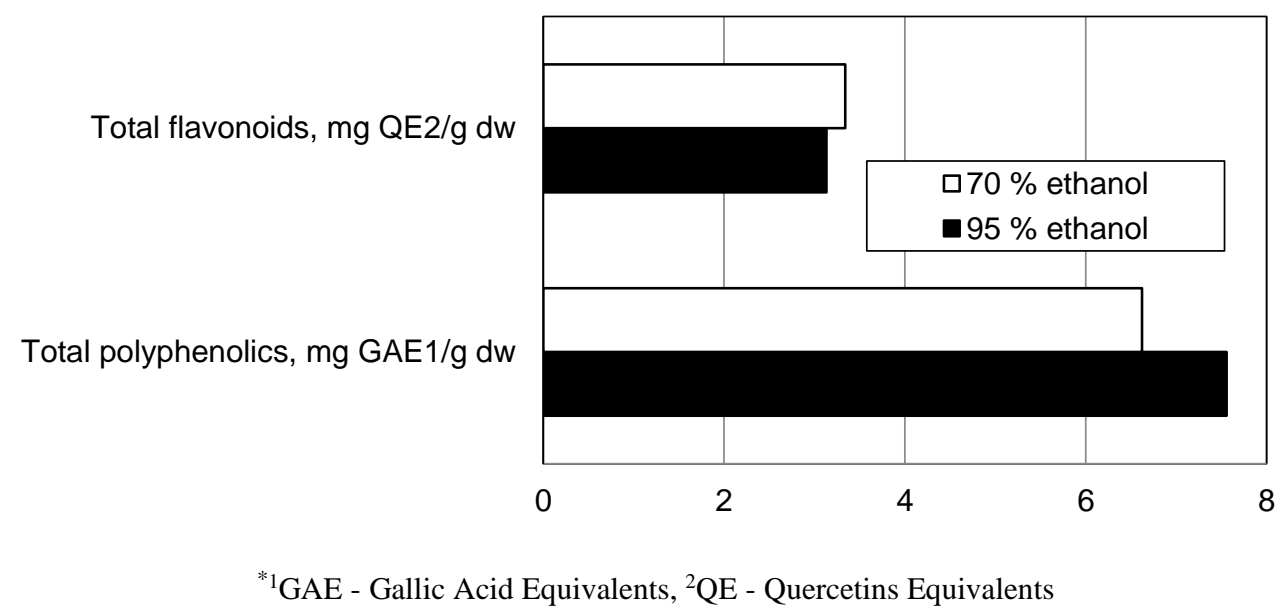

Figure 1. Total polyphenolics and flavonoids content of $\boldsymbol{H}$. arenarium extracts.

\section{Antioxidant activity}

The antioxidant activity of $H$. arenarium extracts, determined via four methods (DPPH, ABTS, FRAP, and CUPRAC) was presented in Figure 2. The anti-radical activity of the samples with $70 \%$ ethanol displayed higher values than the samples with $95 \%$ ethanol by the methods of ABTS and CUPRAC.

Our results were higher than that reported by Babota et al. [23] who determined the antioxidant activity of $70 \%$ ethanol extracts of $\mathrm{H}$. arenarium against the stable synthetic ABTS radical action $(5.82 \pm 0.02 \mathrm{mM}$ TE/g/dw) and the method of DPPH $(17.88 \pm 7.20 \mathrm{mM}$ $\mathrm{TE} / \mathrm{g} / \mathrm{dw})$. Albayrak et al. [24] reported lower values for antioxidant activity $(23.03 \mathrm{mM}$ $\mathrm{TE} / \mathrm{g} / \mathrm{dw}$ and $47.64 \mathrm{mM} \mathrm{TE} / \mathrm{g} / \mathrm{dw}$ ) determined by the method of DPPH for two subspecies of $H$. arenarium from Turkey.

The results for ethanol extracts and their antioxidant activity were in accordance with the total phenolic content and the concentration of flavonoids. 


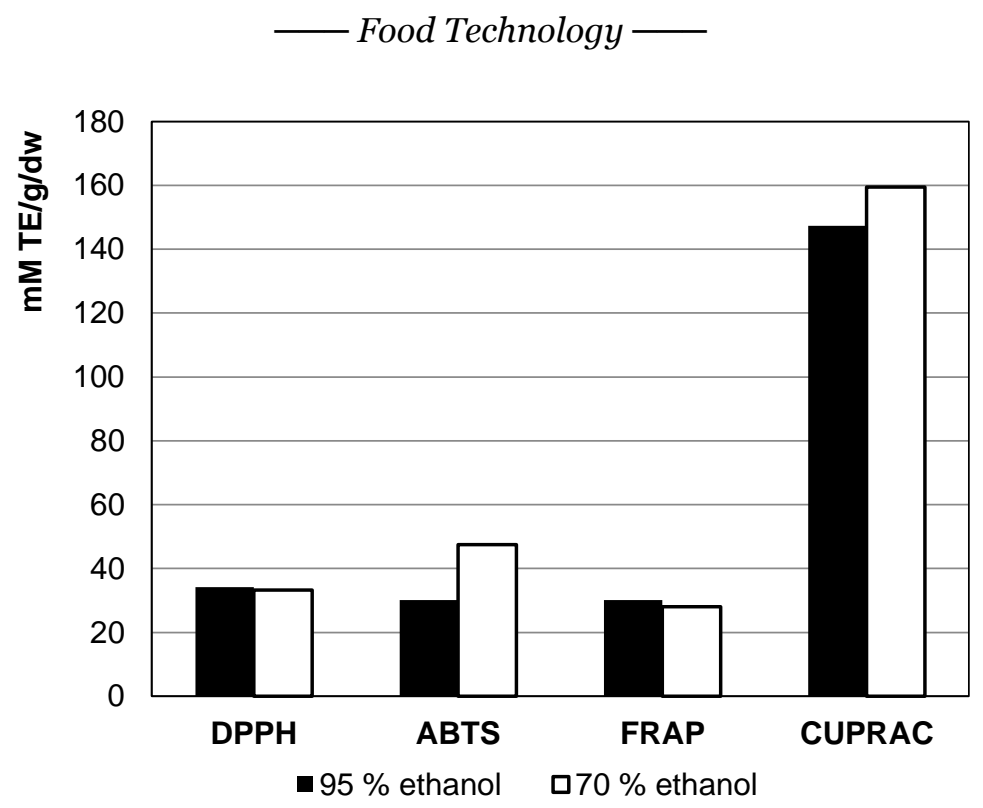

Figure 2. Antioxidant activity of $\boldsymbol{H}$. arenarium extracts

\section{Total Chlorophylls and Carotenoid Content}

The chlorophyll and carotenoid contents in the analysed samples were presented in Table 2. Ethanol is a solvent that dissolves both polar (hydrophilic) and non-polar (hydrophobic/lipophilic) substances. The results showed that the total chlorophyll content predominated in the composition of the sample, followed by carotenoid content.

Table 2

Content of pigments in the dry raw material of $H$. arenarium, $\mu \mathrm{g} / \mathrm{g} \mathrm{dw}$

\begin{tabular}{|c|c|c|c|c|}
\hline \multirow{2}{*}{ H. arenarium } & $\begin{array}{c}\text { Chlorophyll } \\
\mathbf{a}\end{array}$ & $\begin{array}{c}\text { Chlorophyll } \\
\mathbf{b}\end{array}$ & $\begin{array}{c}\text { Total } \\
\text { Chlorophyll }\end{array}$ & $\begin{array}{c}\text { Total } \\
\text { Carotenoid }\end{array}$ \\
\cline { 2 - 5 } & $32.67 \pm 0.21$ & $18.57 \pm 0.08$ & $51.24 \pm 0.24$ & $10.68 \pm 0.11$ \\
\hline
\end{tabular}

According to previous reports [17], the number of porphyrin pigments varied depending on environmental conditions, high-temperature inversions, lack of water and minerals. Higher levels of chlorophyll a (32.67\%) than those of chlorophyll b $(18.57 \%)$ could be a marker of the presence of contamination [25] in both the soil layers and the air where the samples were collected. The extraction method of carotenoids was similar to that of chlorophylls, as they are part of the photosynthetic pigments in plant cells. The values of total chlorophylls and carotenoids in the tested samples may vary depending on the type of solvent used [17], its polarity and the conditions of their extraction. Changes in the content of chlorophyll pigments were a typical abiotic stress associated primarily with induced aging, light stress, nitrogen deficiency and others, in which initially the content of chlorophyll a decreased stronger than chlorophyll $b$. 


\section{- Food Technology}

\section{Conclusions}

1. The qualitative composition of the obtained essential oil from $H$. arenarium from Turkey demonstrated the content of volatile biologically active components with potential for use in the food, cosmetics and pharmaceutical industry,

2. The ethanol extracts from $H$. arenarium from Turkey exhibited pronounced antioxidant properties based on high levels of flavonoids, polyphenols and porphyrin pigments.

Acknowledgements. This work is part of a project supported by the Yozgat Bozok University Scientific Research Projects Unit (BAP; Project Code: 6602a-TBMYO/2-356, Yozgat, Turkey).

\section{References}

1. Eroğlu H., Hamzaoğlu E., Aksoy A., Budak Ü., Albayrak S. (2010), Cytogenetic effects of Helichrysum arenarium in human lymphocytes cultures, Turk J Biol. 34, pp. 253 259.

2. Cui H., G. Zhan Lin L. (2015), Antibacterial activity of Helichrysum italicum oil on vegetables and its mechanisms of action, J. Food Process. Pres., 39(6), pp. 2663-2672.

3. Dombrowicz F., Swiatek L., Kopycki W. (1994), Phenolic acid in inflorescence Helichrysum and herbs Hieracli pilosellae, Pharmazie, 47, pp. 469-470.

4. Radusiene J., Judzentiene A. (2008), Volatile composition of Helichrysum arenarium field accessions with differently coloured inflorescens, Biologia, 54 (2), pp. 116-120.

5. Liu X., King X., Li G. (2019), A process to acquire essential oil by distillation concatenated liquid- liquid extraction and flavonoids by solid-liquid extraction simultaneously from Helichrysum arenarium (L.) Moench inflorescences under ionic liquid- microwave mediated, Sep. Purif. Technol. 209, pp. 164-174.

6. Czinner E., Lemberkovics E., Bihatsi-Karsai E., Vitanyi G., Lelik L. (2000), Composition of the essential oil from the inflorescence of Helichrysum arenarium (L.) Moench, J Essent Oil Res., 12 (6), pp. 728-730.

7. Rancic A., Sokovic M., Vukojevic J., Simic A., Marin P., Duletic-Lausevic S. (2005), Chemical composition and antimicrobial activities of essential oils of Myrrhis odorata (L.) Scop, Hypericum perforatum L. and Helichrysum arenarium (L.) Moench, J Essent Oil Res., 17 (3), pp. 341-345.

8. Moghadam H., Sani A., Sangatash M. (2014), Inhibitory effect of Helichrysum arenarium essential oil on the growth of food contaminated microorganisms, J Essent Oil Bear Pl., 17 (3), pp. 911-921.

9. Tepe B., Sokmen M., Akpulat H., Sokmen A. (2005), In vitro antioxidant activities of the methanol extracts of four Helichrysum species from Turkey, Food Chem., 90, pp. $685-689$.

10. Stankov S., Fidan H., Ivanova T., Stoyanova A., Damyanova, S., Desyk, M. (2018), Chemical composition and application of flowers of false acacia (Robinia pseudoacacia L.), Ukrainian Food Journal.,7 (4), pp. 577-588.

11. Memarzadeh S., Pirbalouti A., Adibnejad M. (2015), Chemical composition and yeld of essential oils from Bakhtiari savory (Satureja bachtiarica Bunge) under different extraction methods, Ind Crops Prod., 76, 809-816. 


\section{Food Technology}

12. Ivanov I., Vrancheva R., Marchev A., Petkova N., Aneva I., Denev P., Georgiev V., Pavlov A. (2014), Antioxidant activities and phenolic compounds in Bulgarian Fumaria species, IJCMAS, 3(2), pp. 296-306.

13. Kıvrak I., Duru M., Öztürk M., Mercan N., Harmandar M., Topçu G. (2009), Antioxidant, anticholinesterase and antimicrobial constituents from the essential oil and ethanol extract of Salvia potentillifolia, Food Chem., 116(2), pp. 470-479.

14. Brand-Williams W., Cuvelier M.E., Berset C. (1995), Use of a free radical method to evaluate antioxidant activity, LWT-Food Sci Technol., 28, pp. 25-30.

15. Benzie I., Strain J. (1996), Ferric reducing ability of plasma (FRAP) as a measure of antioxidant power: The FRAP assay, Anal. Biochem., 239, pp. 70-76.

16. Marchev A., Petrova A., Nedelcheva D., Lazarova I., Trucheva B., Kostova, N., Bankova V., Pavlov A. (2011), GS/MS profiles and antioxidant activity of extract from Lavandula vera MM and Rosa damascena Mill. cell suspension cultures, Scientific works-UFT, 58(2), pp. 183-188.

17. Sumanta N., Haque C.I., Nishika J., Suprakash R. (2014), Spectrophotometric analysis of chlorophylls and carotenoids from commonly grown fern species by using various extracting solvents, Res. J. Chem. Sci., 4 (9), 63-69.

18. Leonardi M., Giovanelli S., Ambryszewska K. E., Ruffoni B., Cervelli C., Pistelli L., Flamini G., Pistelli L. (2018), Essential oil composition of six Helichrysum species grown in Italy, Biochem. Syst. Ecol., 79, pp.15-20.

19. Judzentiene A. Butkiene R. (2006), Chemical composition of the essential oils of wild Helichrysum arenarium (L.) with differently colored inflorescences from Eastern Lithuania, J Essent Oil Res., 18(1), pp. 80-83.

20. Judzentiene A., Charkova T., Misiūnas A. (2019), Chemical composition of the essential oils from Helichrysum arenarium (L.) plants growing in Lithuanian forests, J Essent Oil Res., 31, 4, pp. 305-311.

21. Juliano C., Marchetti M., Campagna P., Usai M. (2019), Antimicrobial activity and chemical composition of essential oil from Helichrysum microphyllum Cambess. subsp. tyrrhenicum Bacch., Brullo \& Giusso collected in South-West Sardinia. S J Biol Sci., 26(5), pp. 897-905.

22. Kürkçüoğlu M., Ağalar H.G., Aksoy A., Başer K.H.C. (2019), Composition of the essential oils of two endemic Helichrysum species in Turkey, Rec Nat Prod., 13(3), pp. 236-242.

23. Babota M., Mocan A., Vlase L., Cris O., Ielciu I., Gheldiu A.M., Vodnar D.C., Crişan G., Păltinean R. (2018), Phytochemical analysis, antioxidant and antimicrobial activities of Helichrysum arenarium (L.) Moench. and Antennaria dioica (L.) Gaertn. flowers. Molecules, 23, pp. 409.

24. Albayrak S., Aksoy A., Sagdic O., Budak U. (2010), Phenolic compounds and antioxidant and antimicrobial properties of Helichrysum species collected from eastern Anatolia, Turkey, Turk J Biol., 34, pp. 463-473.

25. Vicas S., Laslo V., Pantea S., Bandict G. (2010), Chlorophyll and carotenoids pigments from Mistletoe (Viscum album) leaves using different solvents, Fascicula Biol., 2, pp. 213-218. 